\title{
Erratum to: Overexpression and constitutive nuclear localization of cohesin protease Separase protein correlates with high incidence of relapse and reduced overall survival in glioblastoma multiforme
}

\author{
Malini Mukherjee - Tiara Byrd • Vita S. Brawley - Kevin Bielamowicz • \\ Xiao-Nan Li · Fatima Merchant · Saurabh Maitra • Pavel Sumazin • \\ Greg Fuller • Yvonne Kew • David Sun · Suzanne Z. Powell • Nabil Ahmed • \\ Nenggang Zhang • Debananda Pati \\ Published online: 6 June 2014 \\ (c) Springer Science+Business Media New York 2014
}

\section{Erratum to: J Neurooncol}

DOI 10.1007/s11060-014-1458-6

There was an error in the name of author Nabil Ahmed in the original publication. The name is correct in this erratum.

The online version of the original article can be found under doi:10. 1007/s11060-014-1458-6.

M. Mukherjee · T. Byrd · V. S. Brawley $\cdot$ X.-N. Li ·

P. Sumazin $\cdot$ N. Ahmed $\cdot$ N. Zhang $\cdot$ D. Pati

Texas Children's Cancer Center, Baylor College of Medicine,

Houston, TX 77030, USA

M. Mukherjee · T. Byrd · V. S. Brawley · K. Bielamowicz ·

X.-N. Li · P. Sumazin · N. Ahmed · D. Pati $(\bowtie)$

Department of Pediatric Hematology/Oncology, Baylor College

of Medicine, 1102 Bates St., MC3-3320, Houston, TX 77030,

USA

e-mail: dxpati@txch.org; pati@bcm.edu

T. Byrd · V. S. Brawley · K. Bielamowicz · N. Ahmed

Center for Cell and Gene Therapy, Baylor College of Medicine,

Houston, TX 77030, USA

X.-N. Li · N. Ahmed $\cdot$ N. Zhang $\cdot$ D. Pati

The Dan L Duncan Comprehensive Cancer Center, Baylor

College of Medicine, Houston, TX 77030, USA

F. Merchant

Department of Engineering Technology, University of Houston, 4800 Calhoun Rd., Houston, TX 77030, USA

\section{S. Maitra}

Bauer College of Business, University of Houston,

4800 Calhoun Rd., Houston, TX 77024, USA

G. Fuller

Department of Pathology, MD Anderson Cancer Center,

Houston, TX 77030, USA

Y. Kew · D. Sun $\cdot$ S. Z. Powell · N. Ahmed

Methodist Hospital Research Institute, Houston, TX 77030, USA

D. Pati

Molecular and Cellular Biology, Baylor College of Medicine,

Houston, TX 77030, USA 